\title{
'Smoking left atrium': an alarm to be vigilant and aggressive
}

\author{
Basant Kumar, Navin Agrawal, Soumya Patra, Cholenahally Nanjappa Manjunath
}

Department of Cardiology, Sri Jayadeva Institute of

Cardiovascular Sciences and Research, Bangalore, Karnataka, India

\section{Correspondence to} Dr Navin Agrawal, drnavinagrawal@gmail.com

\section{DESCRIPTION}

We are presenting an interesting image of an echocardiographic appearance of spontaneous echo contrast (SEC) in the left atrium (LA), which resembled 'Smoking LA'.

A 40-year-old man presented with severe rheumatic mitral stenosis, with a history of surgical mitral valvotomy and left hemiparesis at the age of 19 years, diagnosed with NYHA class III dyspnoea and orthopnoea since the last 5 months. Subsequently, he was treated successfully with balloon valvuloplasty.

Transthoracic echocardiogram revealed the presence of an enlarged LA with severe mitral stenosis. SEC was seen in LA moving into left ventricle, which appeared to resemble a puff of smoke coming from the LA (videos 1-3 and figures 1 and 2). The echocardiographic image appeared as though the 'LA was smoking'. Diastolic jet of SEC across mitral

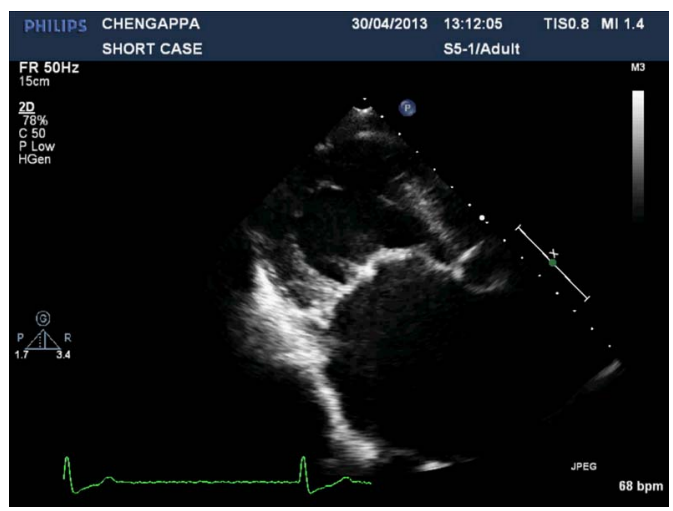

Video 1 A transthoracic echocardiogram in parasternal long axis view showing thickened mitral valve and enlarged left atrium having spontaneous echo contrast moving into left ventricle.

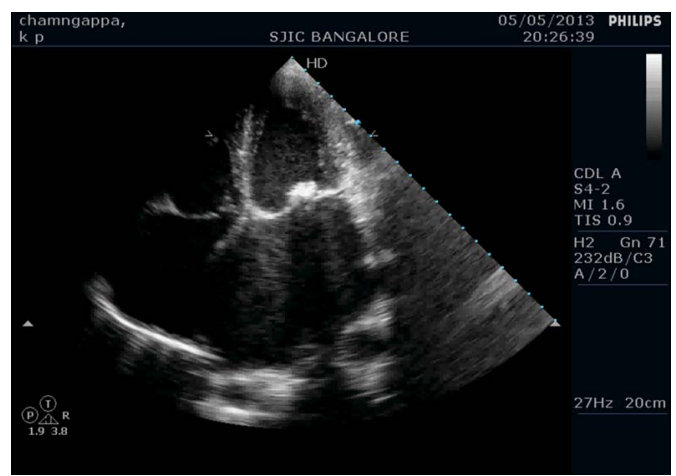

Video 2 A transthoracic echocardiogram in apical four chamber view showing spontaneous echo contrast moving into left ventricle resembling a "puff of smoke".

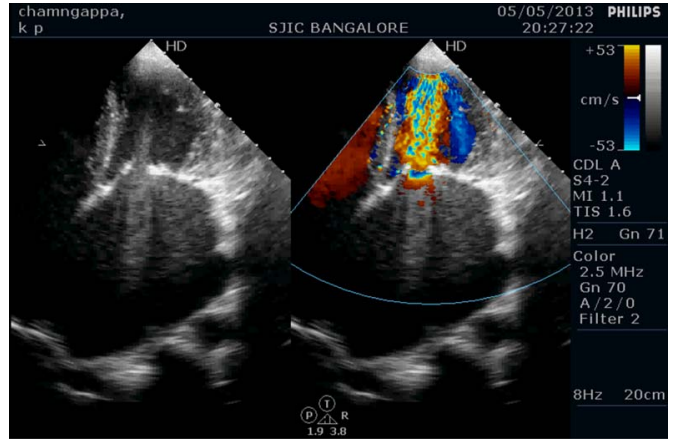

Video 3 A transthoracic echocardiogram in apical four chamber view showing colour Doppler across mitral valve in comparison with one without colour.

valve provides a marker of thrombogenicity in twodimensional echo in the absence of an obvious clot in patients in sinus rhythm, and can be used as a stand-alone marker to assess severity of diseases like mitral stenosis and severe ventricular dysfunction or in slow/stagnant flow states without the requirement of Doppler evaluation. It can be useful in cases planned for elective cardioversion of atrial fibrillation as well as in prognostication of cases after valvuloplasty.

SEC is an echogenic swirling pattern of blood flow caused by an increased ultrasonic backscatter from the aggregation of the cellular components of blood in the conditions of blood stasis or lowvelocity blood flow. Previous studies have graded SEC and have demonstrated its utility in predicting adverse thromboembolic events in sinus rhythm patients, who are otherwise not considered candidates for anticoagulation. ${ }^{1-3}$

This image was an interesting appearance presented by a relatively uncommon manifestation of

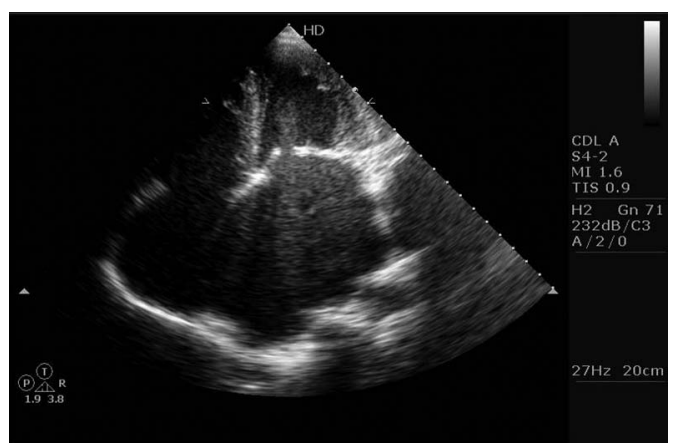

Figure 1 A transthoracic echocardiogram in apical four-chamber view showing large left atrium (LA) with spontaneous echo contrast (SEC), moving from LA to left ventricle (LV) appearing as a 'puff of smoke'. 


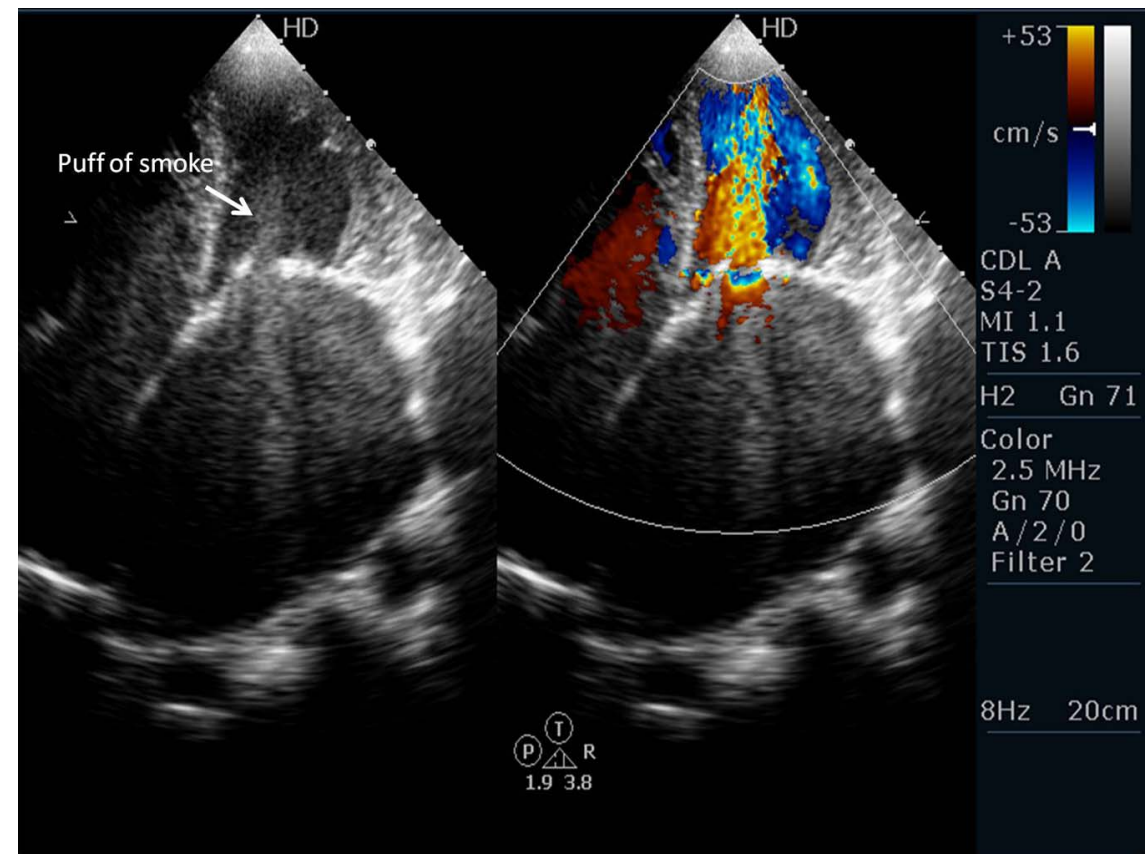

Figure 2 An echocardiogram in apical four-chamber view showing colour comparison of mitral valve flow.

valvular or structural heart disease, which needs timely and vigilant evaluation for prevention of catastrophic thromboembolic complications.

\section{Learning points}

- Spontaneous echo contrast is a marker of increased thrombogenicity in cases with sluggish blood flow in two-dimensional echo in absence of an obvious clot, especially in sinus rhythm patients.

- It may be considered as an indication for anticoagulation and for aggressive follow-up and monitoring for thromboembolic complications, to avoid potentially ignoring a large chunk of patients who are denied anticoagulation therapy despite being at increased risk as has been demonstrated previously.

- It can be taken as an evidence of disease severity and an indication for therapeutic intervention.
Correction notice This article has been corrected since it was published online on 2 July 2013. Videos 1-3 was previously omitted and has now been included.

Contributors All authors have contributed to the manuscript and in patient care. Competing interests None.

Patient consent Obtained.

Provenance and peer review Not commissioned; externally peer reviewed.

\section{REFERENCES}

1 Leung DY, Black IW, Cranney GB, et al Prognostic implications of left atrial spontaneous echo contrast in nonvalvular atrial fibrillation. J Am Coll Cardiol 1994;24:755-62.

2 Daniel WG, Nellessen U, Schroder $E$, et al. Left atrial spontaneous echo contrast in mitral valve disease: an indicator for an increased thromboembolic risk. J Am Coll Cardiol 1988;11:1204-11.

3 Kasliwal RR, Mittal S, Kanojia A, et al. A study of spontaneous echo-contrast in patients with rheumatic mitral stenosis and normal sinus rhythm: an Indian perspective. BeHeart / 1995;74:296-9.

Copyright 2013 BMJ Publishing Group. All rights reserved. For permission to reuse any of this content visit http://group.bmj.com/group/rights-licensing/permissions.

BMJ Case Report Fellows may re-use this article for personal use and teaching without any further permission.

Become a Fellow of BMJ Case Reports today and you can:

- Submit as many cases as you like

- Enjoy fast sympathetic peer review and rapid publication of accepted articles

- Access all the published articles

- Re-use any of the published material for personal use and teaching without further permission

For information on Institutional Fellowships contact consortiasales@bmjgroup.com

Visit casereports.bmj.com for more articles like this and to become a Fellow 